\title{
EL PAPEL DE LA PROSODIA EN LA EXPRESIÓN DE LA IRONÍA EN ESPAÑOL
}

\section{INTRODUCCIÓN}

«La estructura melódica de la frase es como el hilo donde se enhebran las palabras, haciendo de las perlas aisladas un collar.» Amado Alonso (1955: 76)

El contenido o el sentido comunicativo de cualquier enunciado depende de la combinación de los valores de todos los signos emitidos en una situación enunciativa. Una misma combinación sintáctica puede admitir e incitar varias interpretaciones, condicionadas tanto por movimientos corporales y gestos del hablante como por diferentes mecanismos prosódicos (el tono, la intensidad, el ritmo, la duración y las cualidades de la voz). Es más, la prosodia o, más concreto, la entonación, es el recurso más común y el más elemental del enunciado: puede haber enunciados sin forma gramatical, pero $\sin$ entonación, no (Quilis 1993: 426).

Según Couper-Kuhlen (2011: 491) la prosodia abarca «those auditory but non-segmental dimensions of speech which have a variable relation to the words used» así que no pocas veces es decisiva para la comprensión no solo de las oraciones enteras sino también para la interpretación de sus partes. Como el ejemplo más citado en castellano están los marcadores discursivos, cuya función principal es la de guiar las inferencias que se dan en la comunicación (Martín Zorraquino/Portolés 1999: 4057), ya que es justamente el contorno entonativo el que constituye el fenómeno suprasegmental más descrito en los estudios actuales sobre estos elementos (Pereira 2011: 86) ${ }^{1}$. En este trabajo nos interesa entonces cómo influyen los procesos entonativos en la correcta comprensión de la intención comunicativa del hablante, más concreto, de la intención irónica, y si son sistematizables siempre y cuando se utilizan intencionadamente. Para este objetivo se ha realizado un experimento en el que se ha analizado el reconocimiento de la intención irónica en diez enunciados, grabados especialmente para esta ocasión.

\section{IRONÍA VERBAL}

La investigación científica sobre la ironía acompaña a la filosofía desde sus orígenes y ha sido siempre muy heterogénea, de ella se ha ido ocupando todo un abanico de

* barbara.pihler@ff.uni-lj.si

1 Un marcador tan frecuente como bueno puede expresar una amplia gama de matices, a saber, muy diferentes sentimientos (positivos o negativos), modalidad deóntica, puede ser regulador, puede servir para cerrar el discurso, pero puede ser también guía de la ironía dependiendo del contexto en que aparezca y de la entonación que se emplee. 
disciplinas: antropología, filosofía, literatura, psicología, lingüística, pragmática, etc. El término proviene del griego eironéia y se define a menudo como 'burla fina y disimulada' $^{2}$ con lo cual no es de extrañar que la definición retórica tradicional la describa como «un tropo que consiste en decir lo contrario de lo que se quiere hacer entender al destinatario» (Charaudeau/Maingueneau 2005: 340). La ironía en el sentido más amplio abarca tanto la ironía situacional (que depende del contexto extralingüístico) como la ironía verbal que se infiere de las palabras pronunciadas en un determinado contexto (Haverkate 1985) y que es objeto de este estudio. Sin embargo, habrá que destacar ya de entrada que la ironía verbal en realidad no está en las palabras mismas sino que es un resultado del funcionamiento de varios factores y, asimismo, debe ser una «labor colaborativa» (Padilla García 2009: 7) entre el hablante y el oyente ya que no solo es suficiente la intención irónica del hablante sino también la capacidad del interlocutor para reconocerla y aceptarla, para completar así el proceso comunicativo.

La ironía verbal se ofrece en la mayoría de los enfoques «pre-pragmáticos» como una antífrasis que posibilita a los hablantes transmitir los significados implícitos que son intencionadamente contradictorios a las proposiciones contenidas en palabras. Por ejemplo, en una situación donde dos hablantes están sintiendo mucho calor debido a las altas temperaturas estivales, uno le dice irónicamente a otro: «uy, qué frío que hace hoy ¿verdad?»

Sin embargo, entender la ironía como decir algo contrario del sentido literal resulta problemático puesto que se puede aplicar solo a los declaraciones afirmativas, mientras que muchos enunciados irónicos pueden ser también interrogativos o expresivos, o pueden significar ofrecimientos (Haverkate 1985, Utsumi 2000). Observemos el siguiente ejemplo: María se ha preparado la tortilla, pero mientras está lavando los platos, su marido se la come entera. Cuando María se entera de ello, puede expresar la ironía de varias maneras que no simplemente expresan lo contrario del sentido literal, por ejemplo: ¿Quieres un trocito más?; ¿Has visto mi tortilla por aquí?; ¡Cuántas ganas tengo de comer ahora la tortilla!, etc. Parece obvio entonces, que la ironía no consiste en decir algo contrario sino en decir una cosa, con el propósito de dar a entender «otra distinta» (Padilla García 2009) o «muchas cosas a la vez» (Reyes 1990) ${ }^{3}$.

En la segunda mitad del siglo XX aparecen así varias investigaciones que estudian la ironía primero desde la perspectiva de la filosofía del lenguaje (Grice 1975; Haverkate 1985, etc.) y después dentro del marco pragmático (Sperber/Wilson 19864; Reyes 1984, 1990; Escandell Vidal 1999, etc.), centrándose sobre todo en la manera en que se transmiten, a través de ella, los significados implícitos cuando la contradicción no es tan evidente. La ironía es, según estos autores, un procedimiento del lenguaje propiamente pragmático

2 En Diccionario de la Real Academia en línea s/v 'ironía'.

3 Según Grice (1975), por otra parte, una enunciación irónica es posible porque se viola a propósito la máxima de calidad. El interlocutor reconoce la violación, lo que le lleva a inferir el significado contrario de lo dicho.

4 Sperber y Wilson (1978) consideran la ironía como mención, donde la ironía se entiende como una especie de cita por la cual el hablante mencionaría la verbalización de un personaje descalificado que dice algo «ostensiblemente fuera del lugar respecto del contexto» (Charaudeau/ Maingueneau 2005: 340). 
ya que «sólo se percibe en contexto, y depende de las intenciones del locutor y de las capacidades interpretativas del interlocutor» (Reyes 1984: 154). El objetivo central de este tipo de investigaciones es el lenguaje no literal, cuando hay que diferenciar entre el sentido de la oración y el sentido del hablante (Grice 1975; Sperber/Wilson 1986).

Ya se ha dicho que un enunciado es irónico cuando el hablante tiene esta intención y cuando el oyente lo reconoce y acepta como tal. Para que esto sea posible el oyente tiene que identificar una serie de indicadores y marcas que varían según la situación concreta. En general las marcas de la ironía se dividen en tres grandes grupos: las lingüísticas (uso de superlativos, unidades fraseológicas, etc.) ${ }^{5}$, las kinésicas (gestos, risas, etc.), y las fónicas, como por ejemplo entonación, silabeo, pausas y otras (Padilla García 2015: 26), que son las que nos interesan en este estudio. Muecke (1978), uno de los primeros investigadores sobre los elementos indicadores de la ironía verbal, destaca tres factores que condicionan un enunciado irónico: emplear determinados recursos, disimular sentimientos y utilizar ciertas marcas llamadas ironic markers (1978: 365). Según él hay varias clases de marcas irónicas, entre ellas las lingüísticas que asimismo se dividen en las kinésicas, gráficas, fónicas, léxicas y discursivas.

Según el grupo GRIALE ${ }^{6}$ hay que distinguir entre los conceptos de 'marca' e 'indicador' (Attardo 2001, Padilla García 2009 y otros) ya que tienen funciones distintas. Las primeras tienen un valor procedimental ${ }^{7}$ y ayudan a identificar la ironía, mientras que los segundos producen o contienen la ironía en sí mismos ya que suministran ironía de una manera explícita. Los elementos acústicos, como también el tono irónico, pertenecen al primer grupo, es decir a las marcas ya que pueden guiar las inferencias hacia la ironía pero no son imprescindibles para su expresión.

En las últimas décadas los estudios de la ironía, como propone Becerra Valderrama (2011: 7) se han ampliado: se estudia cómo se adquiere la ironía y cuál es su función en la sociedad, y, sobre todo, si verdaderamente existe un tono de voz propiamente irónico que individualiza la ironía de otras figuras y, en el caso de que sí, cómo éste influye o condiciona la comprensión de los enunciados emitidos en un discurso oral. ${ }^{8}$

\section{ENTONACIÓN EN ESPAÑOL: CONCEPTUALIZACIÓN}

Cuando hablamos no solo articulamos sonidos y palabras una tras otra, sino también asignamos melodías a los enunciados para producir diferentes efectos semánticos. A veces la actitud del hablante «se deja implícita y hay que deducirla contando solo con

5 Se han estudiado también ciertas restricciones sintácticas, pero no hay muchas que valgan solo para los enunciados irónicos. De hecho, en español podemos mencionar la anteposición de algunos adjetivos (bonito, menudo, valiente,...) que en esta posición siempre indican una connotación expresiva, ironía, enfado o sarcasmo: ¡Bonita hora de llegar a casa! (véase Haverkate 1985: 349).

6 El grupo de investigación GRIALE (Grupo de investigación sobre ironía y humor en español) está formado por profesores de la Universidad de Alicante que se dedican desde el año 2002 al análisis pragmático de la ironía y el humor.

7 En el sentido de Sperber y Wilson (1994).

8 Sin embargo, solo el hecho de que la ironía existe también en los textos escritos demuestra que la prosodia no es conditio sine que non de la ironía (Reyes 1990 y otros). 
el tono de voz, el contexto y otras pistas paralingüísticas.» (Sperber/Wilson 1994: 292). La prosodia como «música del habla» nos ayuda a usar las palabras y frases más allá de sus cualidades fonéticas y léxicas ya que transmite información de manera similar a los gestos o a los movimientos corporales que se usan en una conversación real (Couper-Kuhlen 2000). Toda esta información forma parte de lo que Poyatos llama esquema triple básico de la comunicación que consiste en lenguaje, paralenguaje y kinésica (Poyatos 1994). Lo básico de este esquema es la consideración de los tres componentes como inseparables, con lo cual forman un verdadero instrumento de la comunicación humana funcionalmente coherente y una estructuración óptima de signos percibidos sensorial e intelectualmente. Por otra parte habrá que destacar también su definición de paralenguaje como «cualidades no verbales y modificadores de la voz y sonidos y silencios independientes con que apoyamos o contradecimos las estructuras verbales y kinésicas simultáneas o alternantes» (Poyatos 1994: 137). Estas cualidades se agrupan en adelante en varias categorías entre las cuales son las cualidades primarias (que se refieren a los rasgos propios de cada persona como la voz, el timbre, la intensidad, el tono, el ritmo) las más interesantes para destacar en el estudio de la ironía ya que pueden mostrar un enunciado como irónico (Alvarado Ortega 2006: 5).

Cestero (2006: 59) advierte que, entre los cuatro sistemas de comunicación no verbal el sistema paralingüístico y el kinésico son básicos o primarios por su implicación directa en cualquier acto de comunicación humana, mientras que el proxémico y el cronémico son secundarios. Los elementos paralingüísticos consisten en, primero, las cualidades físicas del sonido y los modificadores fónicos o tipos de voz; segundo, algunas reacciones fisiológicas o emocionales; y tercero, los elementos cuasi-léxicos como vocalizaciones y consonantizaciones convencionales de escaso contenido léxico (Cestero 2006: 59). A nosotros nos interesa, entre otros factores, la capacidad de las cualidades físicas, es decir el tono, el timbre, la cantidad y la intensidad de matizar la información de un acto comunicativo.

El suprasegmento entonativo es uno de los componentes más complejos de la lengua y un campo de estudio en el que no faltan dificultades, por eso no es de extrañar que a lo largo del siglo XX se ha ido definiendo desde diferentes puntos de vista, según el centro de interés de cada investigador (Quilis 1993: 407). En el ámbito español actual se pueden divisar dos caminos respecto a la definición: desde una perspectiva más amplia (la entonación como la combinación de varios datos como la frecuencia, las pausas, el ritmo, la intensidad) y desde una perspectiva más estricta que se centra en las variaciones de $\mathrm{F}_{0}$ que cumplen una función lingüística a lo largo de la emisión de la voz (p. ej. Padilla García 2009; Cantero 2002).

La descripción de la entonación española empieza en la primera mitad del siglo XX con Navarro Tomás $(1944,1957)$ cuyas definiciones siguen a la escuela británica del «intonational analysis». La entonación es, según este autor, «la línea de altura musical determinada por la serie de sonidos sucesivos que componen una palabra, una frase o un discurso» (Navarro Tomás 1957: 23), mientras que las cualidades físicas del sonido (traducidos los términos del inglés) son tono (ingl. pitch), timbre (ingl. timbre), cantidad (ingl. duration) e intensidad (ingl. intensity). 
Para este estudio es relevante, primero, la definición de Quilis que ve la entonación como «la función lingüísticamente significativa, socialmente representativa e individualmente expresiva de la frecuencia fundamental en el nivel de la oración» (Quilis 1993: 410), es decir que aparte de las funciones lingüísticas de la entonación (integradora ${ }^{9}$, distintiva, y la demarcativa) hay que tener en cuenta también las funciones del nivel sociolingüístico y las funciones del nivel expresivo de la entonación (Quilis 1993, de manera parecida Hidalgo Navarro 2006).

Además, como en este estudio nos interesa la entonación relacionada con un fenómeno fundamentalmente pragmático como es la ironía, es de especial importancia establecer una distinción entre los procesos entonativos lingüístico ${ }^{10}$ es decir convencionales y distintivos que tienen que ver con la entonación sistemática en el sentido de un comportamiento opositivo ${ }^{11}, \mathrm{y}$, por otra parte, la así llamada entonación expresiva (que tiene que ver con la fonoestilítica), es decir las inflexiones particulares que puede realizar un hablante en un contexto determinado señalando su actitud y provocando reacciones diferentes en el oyente (Escandell Vidal 1999: 3944).

Hidalgo Navarro distingue entre la Función Modal Primaria, aglutinadora de las funciones comunicativas básicas del contorno melódico, y la Función Modal Secundaria, asociada a la emotividad del hablante ya que la prosodia actúa como «vehículo de transmisión del contenido emotivo del habla» (2006: 28). En esta dirección estaban investigando ya Lieberman y Michaels (1962) cuando observaban la contribución de la $\mathrm{F}_{0}$ y la amplitud en la transmisión del contenido emotivo y llegaron a diferentes conclusiones, $p$. ej., que la amplitud desempeña una parte importante en el reconocimiento de las emociones; que diferentes hablantes pueden aplicar parámetros acústicos distintos para transmitir un mismo contenido emotivo; que el grado de perturbación de la $\mathrm{F}_{0}$ parece ser un correlato acústico fundamental de los valores emotivos, etc. (en Hidalgo Navarro 2006: 28).

Escandell Vidal (1999) aborda la entonación desde el punto de vista semántico-pragmático y la entiende como la interacción de las características prosódicas que utilizan los hablantes de una lengua con fines comunicativos que sirve «para orientar de manera decisiva la interpretación de los enunciados» (Escandell Vidal 1999: 3944). Desde esta perspectiva la función principal de la entonación es la «prelingüística» (se transforman unidades lingüísticas en unidades comunicativas), aparte de la función lingüística (para preguntar, afirmar,...) y la paralingüística, que sirve para transmitir las actitudes y estados de ánimo del hablante.

9 La función integradora es aquella que posibilita la organización estructural de las secuencias y remite a la estructura informativa ya que las porciones de información lingüística aparecen a través de las unidades entonativas. La entonación así proporciona al hablante un recurso para hacerse entender por el oyente y, al mismo tiempo, permite al oyente reconocer los bloques de información de acuerdo con el propósito de su interlocutor (Hidalgo Navarro 2006: 19).

10 Según Navarro Tomás (1944) el uso lingüístico de la entonación significa «el movimiento espontáneo y emotivo de la voz, normalizado, sistematizado y puesto al servicio de la expresión voluntaria y consciente».

11 Por ejemplo una interrogación absoluta con un tonema final ascendente se opone en español a la aseveración completa neutra, que presenta un tonema final descendente (Hidalgo Navarro 2006). 
Según Prieto, por otra parte, las variaciones melódicas en las lenguas entonativas, como son las lenguas romances, no se usan para distinguir palabras sino para «manifestar una serie de sentidos pragmáticos que afectan generalmente todo el enunciado» (Prieto 2003: 13). Es decir, mediante la entonación el hablante puede expresar su actitud subjetiva respecto del contenido de su mensaje: el modus (frente al dictum que es el sentido referencial). Es más: la entonación es un recurso modalizador por excelencia, que además de la mencionada función expresiva, tiene una función focalizadora en la lengua, con ayuda de la cual el hablante selecciona la información central, y la función demarcativa a través de la cual el hablante divide el discurso en unidades tonales para que el oyente pueda segmentarlo e interpretarlo con mayor facilidad (Prieto 2003: 14).

La entonación es entonces un efecto prosódico en el que colaboran diferentes elementos: tono (nivel tonal o altura musical de un sonido), tonema (inflexión melódica o dirección que sigue la curva entonativa a partir de la última sílaba tónica del grupo fónico ${ }^{12}$ ), acento oracional (un acento principal fonéticamente muy fuerte que determina el límite de una secuencia) y ritmo o tempo del habla, que es el rasgo de duración/ cantidad a nivel discursivo (Hidalgo Navarro 2006: 16). La primera función expresiva de la entonación es, sin duda, indicar la actitud del hablante hacia lo que dice. El problema para reconocer la dicha actitud surge con la aparición de matices subjetivos y contextuales en el nivel de la función modal primaria que se vuelven más complejos en la perspectiva subjetiva.

\subsection{Entonación como señal de la ironía}

En este estudio nos interesa el papel de la entonación en la producción y el reconocimiento de los enunciados irónicos centrándonos en la pregunta de si verdaderamente existe un tono típicamente irónico, como afirman los retóricos y pragmatistas, que ayude al interlocutor a revelar las intenciones del hablante aún sin conocer el contexto situacional.

En los estudios sobre la ironía la entonación a menudo se menciona como «the most common index of ironical intent» (Attardo 2001: 119), aparte de otros medios fonológicos (alargamiento ${ }^{13}$ de sílabas, pausa, risas), morfológicos (usos de las así llamadas expresiones citativas), tipográficos y kinésicos y marcas que dependen del cotexto o contexto.

¿Qué es entonces la entonación irónica? ¿Será posible determinar los patrones entonativos de la ironía que tengan un valor distintivo? ¿Existe un tono típicamente irónico? Hay varios estudios que se dedican en las últimas décadas a este tema en los cuales se

12 En español Quilis distingue entre el grupo fónico, que es «la porción de discurso comprendida entre dos pausas» y el grupo de entonación, que es «la porción de discurso entendida entre dos pausas, entre pausa e inflexión del fundamental, entre inflexión del fundamental y pausa, o entre dos inflexiones del fundamental, que configura una unidad sintáctica más o menos larga o compleja» (Quilis 1993: 419).

13 Cestero (2006: 60) afirma, por ejemplo, que un enunciado exclamativo como ¡Qué bonito jersey lleva! puede resultar irónico si lo producimos con control de labios redondeados o si elevamos el tono y alargamos ciertos sonidos de los términos ‘bonito' y ‘jersey'. 
pueden divisar dos tendencias principales, a saber, unos afirman que parece que no es posible aislar un tono típicamente irónico (también por el hecho de que los patrones melódicos dependen de los elementos diatópicos, diastráticos, diafásicos), mientras que otros defienden que sí es posible identificar ciertas características entonativas generales para los enunciados irónicos respecto a la intensidad, frecuencia, duración y la velocidad de emisión. En la mayoría de estos estudios la entonación irónica se describe como plana $^{14}$ (ni ascendente ni descendente), sin embargo, como advierte Attardo (2001), algunos autores destacan la entonación interrogativa (ascendente) también como marca irónica, Muecke (1978: 370) habla del uso de una «voz suavizada» (softened voice), mientras que otros presentan otros posibles indicadores de la ironía como bajar el tono de una sílaba normalmente acentuada, patrones intencionadamente exagerados (variaciones melódicas) o nasalización (en Attardo 2001: 119). Becerra Valderama, por otra parte, afirma que un enunciado irónico se caracteriza por una «frecuencia fundamental algo más alta en algunos casos, una duración mayor de los enunciados y una intensidad asimismo más alta» (Becerra Valderama 2011: 263).

Al carácter modal de la prosodia desde el estudio de algunos marcadores multimodales de la ironía en inglés se dedica Attardo $(2000,2001)$ y destaca como rasgos efectivos de la ironía el tono, como mecanismo de contraste, y la expresión de la cara. Según él, un enunciado irónico es, en principio, un «enunciado inapropiado» (inappropiate utterance) pero relevante dentro de una enunciación y un contexto determinados, siempre y cuando el interlocutor lo reconozca e interprete como tal. Este proceso es totalmente inferencial y depende solamente de la presunción de la relevancia óptima del enunciado en el sentido de Sperber y Wilson (1986).

Schoentjes (2001) opina que no es problemático reconocer una entonación irónica, pero distingue entre el tono irónico de un texto y la entonación irónica de la palabra, que según él no coinciden de forma total: «mientras que la entonación afecta con frecuencia a un segmento de discurso relativamente corto, el tono se extiende sobre una porción escrita mucho más larga» (2001: 138). Schoentjes destaca así la entonación irónica como el mayor indicador para el reconocimiento de la ironía en la conversación (íbid.).

Es de especial interés para este estudio el trabajo de Padilla García (2004, 2009, 2015) que intenta proporcionar datos e informaciones tanto fonéticas como pragmáticas sobre las marcas e indicadores de la ironía. Padilla García define el tono irónico como «una forma especial de emitir o pronunciar determinados enunciados, caracterizados, además, por otros elementos kinésicos y lingüísticos diferentes de los acústicos» (2009: 6) en cuya definición acústico-melódica habrá que tener en cuenta especialmente tres elementos acústicos: la frecuencia, la intensidad y el tiempo. Por otra parte, desde el punto de vista pragmático, el tono irónico «es una marca pragmática con valor procedimental» cuyas componentes (velocidad de emisión, $\mathrm{F}_{0} \mathrm{y}$ volumen de la voz) son «una serie de posibilidades acústicas que se manifiestan de manera gradual» (íbid.).

14 Padilla García (2009), por otra parte, considera el tono irónico como hiperónimo ya que, según la entonación depende de uno de los cuatro tipos de la enunciación irónica (como vamos a ver en el capítulo 4 de este trabajo). 
Padilla García $(2009,2015)$ ha demostrado en su análisis del tono irónico que, en cuanto al español, la subida de los hercios de la $\mathrm{F}_{0}$ en la inflexión final de la curva melódica del grupo fónico puede constituirse como parámetro útil en la valoración irónica de los enunciados. Por otra parte las marcas acústicas de la ironía son el cambio de la velocidad de emisión y, en menor medida, la elevación del volumen de voz. En la parte aplicativa de este estudio se comprueban algunas de estas marcas.

En este estudio seguimos a Padilla García $(2009,2015)$ en cuanto a la definición de las características principales del tono irónico en español. Sin embargo, coincidimos con Hidalgo Navarro (2014) cuando afirma que las marcas entonativas de ironía aparecen frecuentemente combinadas con otros indicadores fónicos y kinésicos (junto con los factores subjetivos, como carácter personal, estado de ánimo,...) que ayudan al oyente a interpretar correctamente el significado en un evento comunicativo.

\section{4 ¿QUÉ OLOR A PAN TAN BUENO!}

A lo largo de este estudio se ha destacado la naturaleza esencialmente pragmática de la ironía y con el experimento que describimos a continuación quisimos confirmarlo $\mathrm{y}$, al mismo tiempo observar el papel que desempeña la prosodia en su expresión y reconocimiento. En dicho experimento nos propusimos analizar la contribución de la entonación a la comprensión de enunciados irónicos exclamativos tanto conociendo el contexto situacional como en el caso de enunciados aislados. El experimento se llevó a cabo con 30 estudiantes eslovenos de máster en hispánicas en la Universidad de Ljubljana, con el nivel de español entre B2 y C1. Se quería averiguar cómo se interpretaría una misma frase aislada, una vez emitida con la intención irónica y otra vez con una intención no irónica ${ }^{15}$. El grupo I conocía el contexto situacional, mientras que el grupo II no. A los estudiantes se les explicó que iban a escuchar, primero, un ejemplo no irónico del Atlas Interactivo de la entonación del español (AtInEnEs; Prieto/Roseano 2009-2013 $)^{16}$ como enunciado de control y, después, 10 realizaciones del mismo enunciado, entre las cuales algunas habían sido emitidas con la intención irónica y otras no ${ }^{17}$. Los diez enunciados, que habían sido grabados especialmente para el experimento, habían sido emitidos por dos hablantes femeninos de la misma edad y conocidas por los estudiantes ${ }^{18}$ : hablante $\mathrm{G}$, hablante nativa de Madrid, y hablante $\mathrm{B}$, hablante no nativa pero con el nivel del español C2. Además, creemos importante señalar que los diez enunciados, tanto los irónicos como los no irónicos, fueron grabados el mismo día, en

15 Queremos enfatizar una vez más que somos completamente conscientes de la importancia del contexto situacional y el contacto con el hablante para inferir y reconocer las intenciones comunicativas. Sin embargo con el experimento nos interesaba aislar lo más posible los elementos acústicos. De ahí que creáramos una situación comunicativa un tanto artificial.

16 En el Atlas se aplica el modelo AM y el sistema SP_ToBI, el mismo que en nuestro experimento.

17 No se les reveló el número exacto de los enunciados irónicos, que eran seis.

18 Como afirman varios autores (p. ej. Schoentjes 2001) es primordial conocer a nuestro oyente (y sus particularidades fónicas) para entender qué quiere decir, con lo cual nos pareció importante que las dos hablantes les fueran familiares a los oyentes puesto que no iban a tener el contacto directo con ellas (los estudiantes solo contaron con las grabaciones). 
las mismas condiciones físicas (en un aula de la facultad) y con la misma tecnología (micrófono Logitech H390). Como archivos de audio en formato .wav se analizaron más tarde con el programa informático Praat, versión 6.0.19 (Boersma/Weenink 2016).

Por lo que respecta al protocolo del experimento, los estudiantes se dividieron en dos grupos: al grupo I se le presentaron dos contextos posibles, uno no irónico y otro irónico, que estaban proyectados en la pantalla durante todo el tiempo del experimento, mientras que al grupo II no se les dio ninguna información contextual, simplemente se le pidió que se centraran en los elementos fónicos y que decidieran si el enunciado era irónico o no. El único criterio que les servía fue centrarse en los elementos prosódicos, eso sí, habiendo conocido previamente lo que se suponen características básicas para una entonación irónica según Attardo (2001) y Padilla García (2009). Los enunciados se reprodujeron con un ordenador mediante altavoces, cada enunciado se escuchó tres veces.

\subsection{Algunas características acústicas de los enunciados irónicos y no irónicos}

La sintaxis de la oración ha sido igual en todas las diez realizaciones, solo en una realización apareció al final espontáneamente el adverbio ¿no? que en un principio queríamos eliminar, pero después decidimos dejar porque queríamos observar si iba a influir en el reconocimiento de la intención comunicativa. Se trataba de una oración exclamativa, iqué olor a pan tan bueno!, introducida por el operador exclamativo qué seguido de un grupo nominal con el núcleo olor. Tomando en cuenta el contexto en que dicho enunciado se pronuncia irónicamente se trata aquí de una enunciación irónica propiamente dicha (Padilla García 2009: 149) ${ }^{19}$ y de la así llamada ironía focalizada, puesto que aparece en un solo enunciado (Reus 2009: 297) ${ }^{20}$.

El objetivo de la investigación fue observar, primero, si las distintas realizaciones de un mismo enunciado irónico pronunciadas por un mismo hablante comparten o no determinados elementos fónicos que revelen la intención irónica; segundo, si hay paralelismo entre los enunciados irónicos pronunciados por hablantes distintos; $\mathrm{y}$, tercero, cómo influyen estos elementos en el reconocimiento de la intención comunicativa. Nos centramos en los elementos acústicos, sobre todo el tono y la entonación, como la frecuencia fundamental y ondulaciones de la curva entonativa (aunque se han observado también los elementos de la intensidad).

Como ya se ha explicado más arriba, primero se escuchó el enunciado tomado del AtInEnEs (figura 1): modalidad oracional declarativa, exclamativa, variante español peninsular, dialecto madrileño, con las siguientes características acústicas:

El contorno entonativo formado por dos acentos prenucleares ascendentes, cuyo pico está alineado con la sílaba tónica (-lor, en el primer caso, pan, en el segundo),

19 Padilla García distingue entre cuatro tipos de enunciaciones irónicas: la enunciación sarcástica, enunciación falsa o exageradamente sincera, enunciación irónica propiamente dicha y enunciación irónica neutra o plana, que se diferencian según las marcas acústicas y la repercusión del uso de la ironía sobre el oyente (Padilla García 2009: 149).

20 Siempre según el grupo GRIALE, la ironía que se prolonga a través de varios enunciados es la ironía continuada (Reus 2009: 297). 
precedidos por un tono bajo. En el segundo de los acentos prenucleares el tono alto presenta un escalonamiento descendente. El acento nuclear es ascendente precedido por un tono bajo, estando el pico alineado con la sílaba tónica bue-, y el tono alto presenta un escalonamiento ascendente. El contorno finaliza con un tono de frontera bajo. (AtlnEnEs, s.v. «Qué olor a pan tan bueno»)

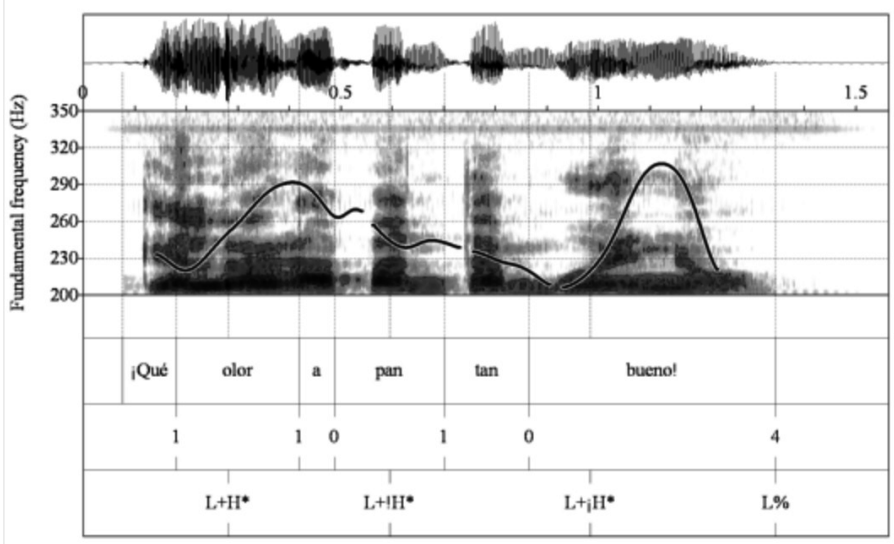

Figura 1: Enunciado no irónico del AtInEnEs

Después se pasó a escuchar los diez enunciados grabados especialmente para el experimento, primero los de la hablante nativa y después los de la hablante no nativa. La administración del experimento ha sido colectiva y se realizó en una sala con condiciones adecuadas de acústica.

\subsubsection{La curva entonativa}

En los gráficos obtenidos del análisis acústico que se añaden en el anexo $5^{21}$ se puede observar una clara diferencia entre la variación tonal de los enunciados irónicos y no irónicos.

En los no irónicos la media de la curva entonativa es considerablemente mayor (siempre sobrepasa los $200 \mathrm{~Hz}$, mientras que en los irónicos no llega a $200 \mathrm{~Hz}$ ):

Figura 2: La media de la curva entonativa (mean Pitch) en los enunciados no irónicos

\begin{tabular}{|l|l|l|}
\cline { 2 - 3 } \multicolumn{1}{c|}{} & Enunciado NoIr1 & Enunciado NoIr21 \\
\hline Hablante G & $231,0 \mathrm{~Hz}$ & $247,4 \mathrm{~Hz}$ \\
\hline Hablante B & $223,5 \mathrm{~Hz}$ & $262,1 \mathrm{~Hz}$ \\
\hline
\end{tabular}

Figura 3: La media de la curva entonativa (mean Pitch) en los enunciados irónicos

\begin{tabular}{|l|l|l|l|}
\cline { 2 - 4 } \multicolumn{1}{c|}{} & Enunciado Ir1 & Enunciado Ir2 & Enunciado Ir3 \\
\hline Hablante G & $191,3 \mathrm{~Hz}$ & $189,8 \mathrm{~Hz}$ & $170,8 \mathrm{~Hz}$ \\
\hline Hablante B & $172,1 \mathrm{~Hz}$ & $191,7 \mathrm{~Hz}$ & $197,5 \mathrm{~Hz}$ \\
\hline
\end{tabular}

21 Solo se reproducen los gráficos de curvas entonativas. 
Si nos fijamos en los puntos de inflexión, es decir, en los puntos en los que se produce un cambio significativo de la curva melódica, podemos observar una notable heterogeneidad en los límites superior e inferior del rango tonal de los seis enunciados irónicos, también cuando son pronunciadas por un mismo hablante (la diferencia de 20 hercios en la media de la curva entonativa). En cuanto a la curva de entonación, Padilla García afirma que «la ironía más sutil, la más ambigua, se caracterizará por una enunciación plana o ligeramente marcada, y la ironía más evidente utilizará una enunciación sarcástica, exagerada» (2009: 156). En nuestros ejemplos analizados la enunciación irónica es plana o ligeramente marcada. Asimismo, en los enunciados irónicos se puede notar la bajada del tono de las sílabas normalmente acentuadas (como decía Haiman 1998), -lor en 'el olor' y bue- en 'bueno'. En algunos enunciados irónicos (por ejemplo BIr1, BIr3, GIr1, GIr3) se pueden observar las así llamadas pausas potenciales que dependen de la voluntad comunicativa del hablante y contribuyen con un valor significativo-expresivo. La consecuencia es también la mayor duración de los enunciados irónicos. La mayoría de dichos enunciados termina con un tonema descendente, uno termina con el ascendente, debido a que se añade el interrogativo ¿no?, mientras que dos terminan con el circunflejo ascendente/descendente. En cuanto a los no irónicos es interesante observar que todos se aproximan bastante al ejemplo del AtInEnEs y finalizan con un tono de frontera bajo, aunque dos con un tonema circunflejo.

Las oraciones que empiezan con una forma por sí misma exclamativa colocan de ordinario el tono principal sobre dicha palabra, haciendo descendiente el resto de la frase, como advierte Navarro Tomás (1957: 233). En los enunciados analizados este no parece ser el caso ya que el tono principal recae sobre 'bueno'. El mismo autor añade que cuando en una misma frase hay dos o más palabras que queremos poner de relieve, hacemos que cada una de ellas, dentro de la línea general de la entonación, ocupe una altura preeminente, resultando una ondulación muy marcada entre las sílabas fuertes de dichas palabras y las demás sílabas de la frase (íbid.). Sin embargo, recordemos que Quilis (1993: 453), en cuanto a las oraciones exclamativas, destaca un descenso muy acusado del fundamental desde la primera sílaba acentuada, o por un fundamental muy bajo y plano. Como ya se ha mencionado, en muchos estudios se destaca lo plano de la enunciación irónica y en parte lo confirma también este estudio.

Se pueden observar, además, diferencias en relación con las variaciones de frecuencia entre las dos hablantes, debido a las características personales y, asimismo, al hecho de que solo G sea una hablante nativa. Sin embargo, parece que estas diferencias en el tono no influyeron de manera decisiva en el reconocimiento de la intención irónica, como veremos a continuación.

\subsubsection{La intensidad y la duración}

Abelda Marco (2012) advierte que una conversación en situaciones normales suele registrar $60 \mathrm{~dB}$. No obstante, en las grabaciones se capta y mide también el ruido ambiental, por eso los resultados pueden ascender. En una conversación coloquial se suele registrar una media de 77,5 dB de intensidad (Abelda Marco 2012) con lo cual 
podemos observar que las máximas alcanzadas tanto en todos los enunciados irónicos de la hablante $\mathrm{G}$ como en los de la hablante B son bajas:

Figura 4: La media de intensidad (mean-energy Intensity) en los enunciados irónicos

\begin{tabular}{|l|l|l|l|}
\cline { 2 - 4 } \multicolumn{1}{c|}{} & Enunciado Ir1 & Enunciado Ir2 & Enunciado Ir3 \\
\hline Hablante G & $73,5 \mathrm{~dB}$ & $70,5 \mathrm{~dB}$ & $68,8 \mathrm{~dB}$ \\
\hline Hablante B & $62,3 \mathrm{~dB}$ & $71,9 \mathrm{~dB}$ & $73,7 \mathrm{~dB}$ \\
\hline
\end{tabular}

Figura 5: La media de intensidad (mean-energy Intensity) en los enunciados no irónicos

\begin{tabular}{|l|l|l|}
\cline { 2 - 3 } \multicolumn{1}{c|}{} & Enunciado NoIr1 & Enunciado NoIr21 \\
\hline Hablante G & $76,0 \mathrm{~dB}$ & $75,9 \mathrm{~dB}$ \\
\hline Hablante B & $69,7 \mathrm{~dB}$ & $71,9 \mathrm{~dB}$ \\
\hline
\end{tabular}

El hecho de que la media de intensidad de los ejemplos analizados sea en general más baja en los enunciados irónicos ${ }^{22}$ da a entender que la pronunciación irónica no es enfática, tampoco marcada, como lo es, por ejemplo, la pronunciación descortés (Abelda Marco, 2012: 526). Este hecho también concuerda con la descripción de Padilla García (2009) sobre el tono irónico en la enunciación irónica propiamente dicha, ya que según sus investigaciones ésta carece de aumento del volumen.

Se puede observar la mayor velocidad en los enunciados del hablante nativo, lo que era de esperar; asimismo se puede observar una cantidad mayor en los enunciados irónicos que en los no irónicos, lo que se debe a los alargamientos fonéticos y un tempo ralentizado:

Figura 6: Velocidad del habla en los enunciados irónicos en segundos

\begin{tabular}{|l|l|l|l|}
\cline { 2 - 4 } \multicolumn{1}{c|}{} & Enunciado Ir1 & Enunciado Ir2 & Enunciado Ir3 \\
\hline Hablante G & 1.18 & 1.20 & 1.50 \\
\hline Hablante B & 1.50 & 1.23 & 1.66 \\
\hline
\end{tabular}

Figura 7: Velocidad del habla en los enunciados no irónicos en segundos

\begin{tabular}{|l|l|l|}
\cline { 2 - 3 } \multicolumn{1}{c|}{} & Enunciado NoIr1 & Enunciado NoIr21 \\
\hline Hablante G & 1.17 & 1.21 \\
\hline Hablante B & 1.22 & 1.36 \\
\hline
\end{tabular}

Se ha confirmado entonces que los enunciados irónicos se caracterizan por una curva entonativa más plana y por una intensidad baja, se ha confirmado la ralentización de la emisión ${ }^{23}$ de una manera más evidente como si con ello el enunciado tuviera más

22 El enunciado no irónico IrG1 posee, además la intensidad más alta: 81,8 dB.

23 Por ejemplo el alargamiento de los sonidos en el adjetivo final bueno que es el lugar sobre el que recae el 'peso irónico'. 
carga informativa (véase también Padilla 2009), pero no el aumento del volumen. También se ha confirmado en parte el aumento de la $\mathrm{F}_{0}$ en la inflexión final de la curva, lo que es según Padilla García (2009), característico de los enunciados irónicos.

\subsection{Reconocimiento de la intención irónica}

Como ya se ha mencionado, a los oyentes se les dividió en dos grupos ya que nos interesaba conocer cuál será la diferencia entre los que sí conocían el contexto y los que no. El contexto no irónico (A) está sacado del AtInEnEs: entras en una panadería, notas un olor a pan muy bueno y se lo dices a la panadera. Por otro lado, el contexto irónico (B) es nuestro: llegas a casa con tu amiga, huele mal, tu pareja, que acaba de salir, ha quemado el pan y le dices a tu amiga: qué olor a pan tan bueno.

Abajo se recogen los datos sobre los aciertos en el grupo I:

Figura 8: porcentajes de acierto en el reconocimiento de los enunciados no irónicos con contexto situacional (grupo I)

\begin{tabular}{|l|l|l|}
\cline { 3 - 3 } \multicolumn{2}{c|}{} & Porcentaje/número de aciertos (N=15) \\
\hline \multirow{2}{*}{ hablante G } & Enunciado NoIrG1 & $87 \%(13)$ \\
\cline { 2 - 3 } & Enunciado NoIrG2 & $93 \%(14)$ \\
\hline hablante B & Enunciado NoIrB1 & $80 \%(12)$ \\
\cline { 2 - 3 } & Enunciado NoIrB2 & $93 \%(14)$ \\
\hline
\end{tabular}

Figura 9: porcentajes de acierto en el reconocimiento de los enunciados irónicos con contexto situacional (grupo I)

\begin{tabular}{|l|l|l|}
\cline { 3 - 3 } \multicolumn{2}{c|}{} & Porcentaje/número de aciertos (N=15) \\
\hline \multirow{3}{*}{ hablante G } & Enunciado IrG1 & $73 \%(11)$ \\
\cline { 2 - 3 } & Enunciado IrG2 & $80 \%(12)$ \\
\cline { 2 - 3 } & Enunciado IrG3 & $60 \%(9)$ \\
\hline \multirow{3}{*}{ hablante B } & Enunciado IrB1 & $53 \%(8)$ \\
\cline { 2 - 3 } & Enunciado IrB2 & $66 \%(10)$ \\
\cline { 2 - 3 } & Enunciado IrB3 & $73 \%(11)$ \\
\hline
\end{tabular}

En cuanto a los enunciados no irónicos tal vez sorprende el hecho de que los enunciados no irónicos del hablante nativo $\mathrm{G}$ no hayan sido reconocidos por todos los oyentes, sobre todo porque antes se había escuchado un enunciado no irónico con la misma variante dialectal (madrileña) y en el anexo se pueden observar las semejanzas en cuanto al acento y la curva del fundamental. Pero cabe volver a decir que los oyentes no eran hablantes nativos de español, y es un hecho que, aparte de ciertas características de entonación comunes a los dos idiomas en cuestión (español y esloveno), existen también las circunstancias especiales (la amplitud y la extensión de los intervalos, la combinación de las inflexiones, las curvas melódicas particulares), características de cada lengua como también de cada individuo. Con lo cual en un futuro sería interesante, si 
no necesario, repetir el mismo experimento con hablantes nativos de español.

En cuanto a los ejemplos irónicos el porcentaje de aciertos es más alto en el grupo I lo que era de esperar ya que disponían de los dos posibles contextos situacionales. Si observamos la curva melódica de los enunciados con menos acierto (Enunciado IrG3 donde un tercio de los hablantes no reconoció la entonación irónica y el Enunciado IrB1, donde casi la mitad no acertó) podríamos atribuirlo quizás al tono más grave y a que tenía menos aumentos y disminuciones de la frecuencia fundamental.

En el grupo que no disponía de contextos previos se nota un descenso en cuanto a los aciertos tanto de los enunciados irónicos como de los no irónicos. Los mismos enunciados reciben menos aciertos, lo que era de esperar:

Figura 10: porcentajes de acierto en el reconocimiento de los enunciados no irónicos sin contexto situacional (grupo II)

\begin{tabular}{|l|l|l|}
\cline { 3 - 3 } \multicolumn{2}{c|}{} & Porcentaje/número de aciertos (N=15) \\
\hline \multirow{2}{*}{ hablante G } & Enunciado NoIr G 1 & $53 \%(8)$ \\
\cline { 2 - 3 } & Enunciado NoIr G 2 & $67 \%(10)$ \\
\hline hablante B & Enunciado NoIrB1 & $60 \%(7)$ \\
\cline { 2 - 3 } & Enunciado NoIrB2 & $53 \%(8)$ \\
\hline
\end{tabular}

Figura 11: porcentajes de acierto en el reconocimiento de los enunciados irónicos sin contexto situacional (grupo II)

\begin{tabular}{|l|l|l|}
\cline { 3 - 3 } \multicolumn{2}{c|}{} & Porcentaje/número de aciertos (N=15) \\
\hline \multirow{3}{*}{ hablante G } & Enunciado IrG1 & $40 \%(6)$ \\
\cline { 2 - 3 } & Enunciado IrG2 & $53 \%(8)$ \\
\cline { 2 - 3 } & Enunciado IrG3 & $33 \%(5)$ \\
\hline \multirow{3}{*}{ hablante B } & Enunciado IrB1 & $33 \%(5)$ \\
\cline { 2 - 3 } & Enunciado IrB2 & $47 \%(7)$ \\
\cline { 2 - 3 } & Enunciado IrB3 & $53 \%(8)$ \\
\hline
\end{tabular}

Lo que llama la atención en cuanto a los resultados del grupo II (pero también del grupo I) es el hecho de que hay un porcentaje considerablemente alto (casi 50\%) de los que han encontrado la intención irónica en los enunciados que no han sido emitidos con esta intención. Este hecho los atribuimos a la ausencia del contexto previo. Es obvio que aquí la prosodia no parece resultar suficientemente informativa. Teniendo en cuenta que los oyentes siempre estamos buscando la relevancia óptima de cualquier enunciado que rija el menor esfuerzo posible, como ya nos demostraron Sperber y Wilson (1986), se puede entender que los que no disponían de información contextual, partían de sus propios contextos mentales.

Creemos importante señalar el hecho de que el enunciado con el porcentaje de aciertos más alto en los dos grupos (grupo I: $80 \%$, grupo II: $53 \%$ ) ha sido el enunciado IrG2, que termina con la juntura terminal ascendente, puesto que la hablante añade el adverbio ¿no?, que como «ironía cómplice» (Hidalgo Navarro 2014: 472) busca acuerdo 
con el interlocutor. Obviamente este hecho ha servido como ayuda para reconocer más fácilmente la ironía.

Como los oyentes conocían a las hablantes era de esperar que iban a ser más fácilmente reconocibles las intenciones irónicas, puesto que estaban familiarizados con sus inflexiones particulares. Sin embargo, hemos visto que aún con el contexto previo el porcentaje de aciertos en ningún caso ha sido el 100\%.

\section{CONCLUSIÓN}

«Irony markers cannot be defined as infallible pointers to irony» (Muecke 1978: 365)

Con la ironía el hablante expresa su actitud hacia lo dicho y hacia el interlocutor y para ello utiliza recursos variados, entre ellos también la entonación que es, como se ha demostrado también en el experimento, una guía estratégica importante dentro de la dinámica del sentido en un intercambio comunicativo.

Sin embargo, como se ha podido ver, es difícil reconocer la intención irónica de un enunciado sin previamente conocer un contexto situacional, con lo cual se puede concluir que solo las propiedades melódicas de un enunciado no aseguran el reconocimiento de las intenciones comunicativas por mucho que se esfuerce el hablante. Así se han confirmado en parte las conclusiones de otros estudios (Becerra Valderrama 2012, Bryant/Fox 2005) de que solo la prosodia no es suficiente para que los interlocutores reconozcan las intenciones irónicas pero que ésta sí tiene la función auxiliar ya que facilita una transmisión más eficaz de la intención comunicativa. Y no hay que olvidar que la ironía a menudo no se marca articulatoriamente ya que depende sobre todo de los conocimientos compartidos y del contexto. Al fin y al cabo, estamos de acuerdo con Poyatos (1994: 130), cuando afirma que los tres componentes del esquema comunicativo, lenguaje, paralenguaje y kinésica, son inseparables ya que forman un verdadero instrumento de la comunicación humana funcionalmente coherente, con lo cual la ausencia de la posibilidad de observar el tercero en nuestro experimento ha sido claramente significativo.

El experimento descrito, que sin duda necesitaría una repetición más sistematizada y elaborada, es solo una pequeña muestra en la que se han confirmado algunos patrones comunes de los que se habla en los estudios sobre las enunciaciones irónicas, mientras que para establecer las conclusiones definitivas habrá que analizar un corpus mucho más amplio.

\section{Bibliografía}

ABELDA MARCO, Marta (2012) «Recursos fónicos descorteses: datos acústicos y metodología para su identificación.» En: J. H. Escamilla Morales/G. Vega (eds), Miradas multidisciplinares a los fenómenos de cortesía en español. Baranquilla/ Estocolmo: Universidad de Atlántico, 520-544.

ALVARADO ORTEGA, Belén (2006) «Las marcas de la ironía.» Interlingüística 16, $1-11$. 
ATTARDO, Salvatore (2000) «Irony markers and functions: Towards a goal-oriented theory of irony and its processing.» $R A S K 12,3-20$.

ATTARDO, Salvatore (2001) Humorous Texts: A Semantic and Pragmatic Analysis. Berlin: Mouton De Gruyter.

BECERRA VALDERRAMA, María (2011) El papel de la prosodia y el contexto en la comprensión y producción de dos formas de ironía en español. Tesis doctoral. Madrid: Universidad Autónoma de Madrid. https://repositorio.uam.es/

BECERRA VALDERRAMA, María (2012) «Rasgos prosódicos en la producción de dos formas de ironía en español.» Lingüística 28, 191-205.

BOERSMA Paul/David WEENINK (2016) Praat: doing phonetics by computer [Computer program]. Versión 6.0.19. http://www.praat.org/

BRYANT, Gregory A./Jean E. FOX TREE (2005) «Is there an Ironic Tone of Voice?» Language and Speech 48/3, 257-277. http://dx.doi.org/10.1177/002383090504800 30101

CANTERO, Francisco (2002) Teoría y análisis de la entonación. Barcelona: Edicions de la Universitat de Barcelona.

CESTERO, Ana (2006) «La comunicación no verbal y el estudio de su incidencia en fenómenos discursivos como la ironía», ELUA 20, 57-77.

CHARAUDEAU, Patrick/Dominique, MAINGUENEAU (2005) Diccionario de análisis del discurso. Buenos Aires: Amorrortu.

COUPER-KUHLEN, Elizabeth (2000) «Prosody.» En: S. D’hondt/J. Östman/J. Verschueren (eds), The Pragmatics of Interaction. Amsterdam: John Benjamins, 174-186.

COUPER-KUHLEN, Elizabeth (2011) «Pragmatics and Prosody: Prosody as a Social Action.» En: W. Bublitz/N. Norrick (eds), Foundations of Pragmatics. Berlin: Mouton de Gruyter, 491-510.

ESCANDELL VIDAL, Victoria (1999) «Los enunciados interrogativos. Aspectos semántico y pragmático.» En: I. Bosque/V. Demonte (eds), Gramática descriptiva de la lengua española, 3. Madrid: Espasa Calpe, 3929-3992.

GRICE, Paul (1975) «Logic and conversation.» En P. Cole/J. Morgan (eds), Syntax and semantics 3: Speech acts. New York: Academic Press, 41-51.

HAVERKATE, Henk (1985) «La ironía verbal: un análisis pragmalingüístico.» Revista Española de Lingüística XV, 343-389.

HIDALGO NAVARRO, Antonio (2006) Aspectos de la entonación española: viejos y nuevos enfoques. Madrid: Arco/Libros.

HIDALGO NAVARRO, Antonio (2014) «Fonética o fonología: ¿por dónde debe empezar la descripción de la entonación española?.» En: Y. Congosto Martín/L. Montero Curiel/A. Salvador Plans (eds), Fonética Experimental, Educación Superior e Investigación, vol. 3 Prosodia. Madrid: Arco/Libros.

LIEBERMAN, Philip/Sheldon B. MICHAELS (1962) «Some Aspects of Fundamental Frequency and Envelope Amplitude as Related to the Emotional Content of Speech.» J. Acoust. Soc. Am. 34, 922-927. 
MARTÍN ZORRAQUINO, Marta/José PORTOLÉS (1999) «Los marcadores del discurso». En: I. Bosque/V. Demonte (eds), Gramática descriptiva de la lengua española 3. Madrid: Espasa Calpe, 4051-4212.

MUECKE, Douglas Colin (1978) «Irony markers.» Poetics 7, 363-375.

NAVARRO TOMÁS, Tomás (1944) Manual de entonación española. Madrid: Guadarrama.

NAVARRO TOMÁS, Tomás (1957) Manual de pronunciación española. New York: Hafner Publishing Company.

PADILLA GARCÍA, Xose (2004) «El tono irónico: estudio pragmático.» Español Actual 81, 85-98.

PADILLA GARCÍA, Xose (2009) «Marcas acústico-melódicas: el tono irónico.» En: Ruiz Gurillo L./X. Padilla Garcia (eds), Dime cómo ironizas y te diré quién eres. Una aproximación pragmática a la ironía. Frankfurt am Main: Peter Lang.

PADILLA GARCÍA, Xose (2015) La pronunciación del español. Fonética y enseñanza de lenguas. Publicacions de la Universitat d'Alacant.

PEREIRA, Daniel Ignacio (2011) «Análisis acústico de los marcadores discursivos a ver, bueno, claro, vale, ¿cómo? y ya.» Onomázein 2/24, 85-100.

POYATOS, Fernando (1994) La comunicación no verbal. Madrid: Istmo.

PRIETO, Pilar (2003) «Teorías lingüísticas de la entonación.» En: P. Prieto (ed.), Teorías de la Entonación. Barcelona: Ariel, 13-33.

PRIETO, Pilar/ Paolo, ROSEANO (coord) (2009-2013) Atlas interactivo de la entonación del español. http://prosodia.upf.edu/atlasentonacion/

QUILIS, Antonio (1975) «Las unidades de la entonación.» Revista Española de Lingüística 5, 261-279.

QUILIS, Antonio (1993) Tratado de fonología y fonética españolas. Madrid: Gredos.

REUS, Boyd-Swan (2009) «Cómo se manifiesta la ironía en un texto escrito.» En: L. Ruiz Gurillo/X. Padilla Garcia (eds), Dime cómo ironizas y te diré quién eres. Una aproximación pragmática a la ironía. Frankfurt am Main: Peter Lang.

REYES, Graciela (1984) Polifonía textual: la citación en el relato literario. Madrid: Gredos.

REYES, Graciela (1990) La pragmática lingüistica. Barcelona: Montesinos.

RUIZ GURILLO, Leonor (2009) «¿Cómo se gestiona la ironía en la conversación?» RILCE 25/2, 363-377. http://hdl.handle.net/10045/24051

SCHOENTJES, Pierre (2001/2003) La poética de la ironía. Madrid: Gredos.

SPERBER, Dan/Deirdre WILSON (1986/1994) La Relevancia. Comunicación y procesos cognitivos. Madrid: Visor.

UTSUMI, Akira (2000) «Verbal irony implicit display of ironic environment: distinguishing ironic utterances from nonirony.» Journal of Pragmatics 32, 1777-1806. http://dx.doi.org/10.1016/S0378-2166(99)00116-2 


\section{EL PAPEL DE LA PROSODIA EN LA EXPRESIÓN DE LA IRONÍA EN ESPAÑOL}

Cuando la ironía verbal, fenómeno intrínsecamente polifónico, forma parte de un discurso oral, a menudo va acompañada de una entonación, de un tono y de un acento particulares (Ruiz Gurillo 2009, Becerra Valderrama 2011). Por lo tanto, la prosodia llega a formar parte significativa de la información paralingüística en una conversación real (Poyatos 1994, Couper-Kuhlen 2000), desempeñando no pocas veces el papel decisivo para el reconocimiento y la correcta interpretación de la ironía verbal por parte del interlocutor. En español hay pocos patrones sintácticos que posibiliten el enunciado irónico (p. ej. la anteposición del adjetivo según Haverkate 1985), de ahí que el papel de la entonación, posiblemente el fenómeno lingüístico más influyente en la comunicación oral, merezca más atención, aunque su estudio no se ha considerado siempre prioritario.

Este trabajo tiene como objetivo, primero, mostrar la relevancia pragmática de la prosodia en la producción de los enunciados irónicos y, segundo, observar los factores que determinan la entonación irónica en español, examinando su funcionamiento en ejemplos concretos del discurso oral. Para este objetivo se han comparado ejemplos de enunciados irónicos con no irónicos, especialmente grabados para esta ocasión y analizados con ayuda del programa informático Praat. La comparación, cuyo principal objetivo ha sido determinar el papel de la prosodia en el reconocimiento de la intención irónica sin o con el contexto situacional, se ha realizado a través de un experimento con treinta estudiantes de máster del departamento de lengua y literatura españolas de la Facultad de filosofía y letras de la Universidad de Ljubljana.

Palabras clave: entonación, prosodia, ironía, discurso oral

\section{Summary}

\section{THE ROLE OF PROSODY IN THE EXPRESSION OF IRONY IN SPANISH}

When verbal irony, an intrinsically polyphonic phenomenon, forms a part of oral discourse, it is often accompanied by a particular intonation, tone and accent (Ruiz Gurillo 2009; Becerra Valderrama 2011). Therefore, prosody becomes a significant part of the paralinguistic information in real conversation (Poyatos 1994; Couper-Kuhlen 2000), often playing the decisive role for the recognition and correct interpretation of verbal irony by the interlocutor. In Spanish there are few syntactic patterns that enable the ironic statement (e.g. the anteposition of adjectives according to Haverkate 1985). Hence, intonation, arguably the most influential linguistic phenomenon in oral communication, deserves more attention, although it has not always been considered a priority.

This article aims to, first, show the pragmatic relevance of prosody in the production of ironic statements and, second, observe the factors that determine the ironic intonation in Spanish, while examining its performance in specific examples of oral 
discourse. For this purpose, examples of ironic statements have been compared with non-ironic statements and analyzed using Praat software. The comparison, whose main objective was to determine the role of prosody in the recognition of the ironic intent with or without the situational context, was carried out in an experiment with thirty students in the Master's Degree program in Spanish at the Faculty of Arts of the University of Ljubljana.

Keywords: intonation, prosody, irony, oral speech

\section{Povzetek \\ VLOGA PROZODIJE PRI IZRAŽANJU IRONIJE V ŠPANSKEM JEZIKU}

Ko se verbalna ironija, po svojem bistvu večglasje, pojavi v govorjenem sporazumevanju, jo pogosto spremljajo svojevrstna intonacija, tonski potek in vrsta naglasa (Ruiz Gurillo 2009; Becerra Valderrama 2011). Prozodija potemtakem igra pomembno vlogo znotraj parajezikovnega sklopa informacij v konkretni sporazumevalni situaciji (Poyatos 1994; Couper-Kuhlen 2000) in je pogosto celo odločilna pri poslušalčevem prepoznavanju in ustrezni interpretaciji ironično rabljenih besed. Španski jezik razpolaga z manj skladenjskimi vzorci, ki bi omogočali ironične pomene (npr. položaj pridevnika po Haverkateju 1985), iz česar sledi, da si raziskovanje intonacijske vloge, verjetno ključnega sredstva pri govorjenem sporazumevanju, v španskem prostoru zasluži več pozornosti, čeprav temu ni bilo vedno tako.

Cilja pričujoče študije sta dva: prvič, prikazati pragmatično relevantnost prozodije pri tvorjenju ironičnih izjav in drugič, na podlagi konkretnih primerov govorjene interakcije analizirati tiste prozodične dejavnike, ki opredeljujejo in zagotavljajo ironično intonacijo $\mathrm{v}$ španskem jeziku. $\mathrm{V}$ ta namen je bila s pomočjo računalniškega orodja Praat opravljena primerjalna akustična analiza ironičnih in ne-ironičnih izjav, posebej posnetih za potrebe te raziskave. V eksperimentu, pri katerem je sodelovalo trideset študentov španskega jezika in književnosti na Filozofski fakulteti Univerze v Ljubljani, se razišče tudi, v kolikšni meri prozodija pripomore k prepoznavanju ironičnega namena govorca, če poslušalci situacijskih okoliščin izjavljanja ne poznajo.

Ključne besede: intonacija, prozodija, ironija, govorjeni jezik 


\section{ANEXOS: GRÁFICOS DE LOS ENUNCIADOS ANALIZADOS}
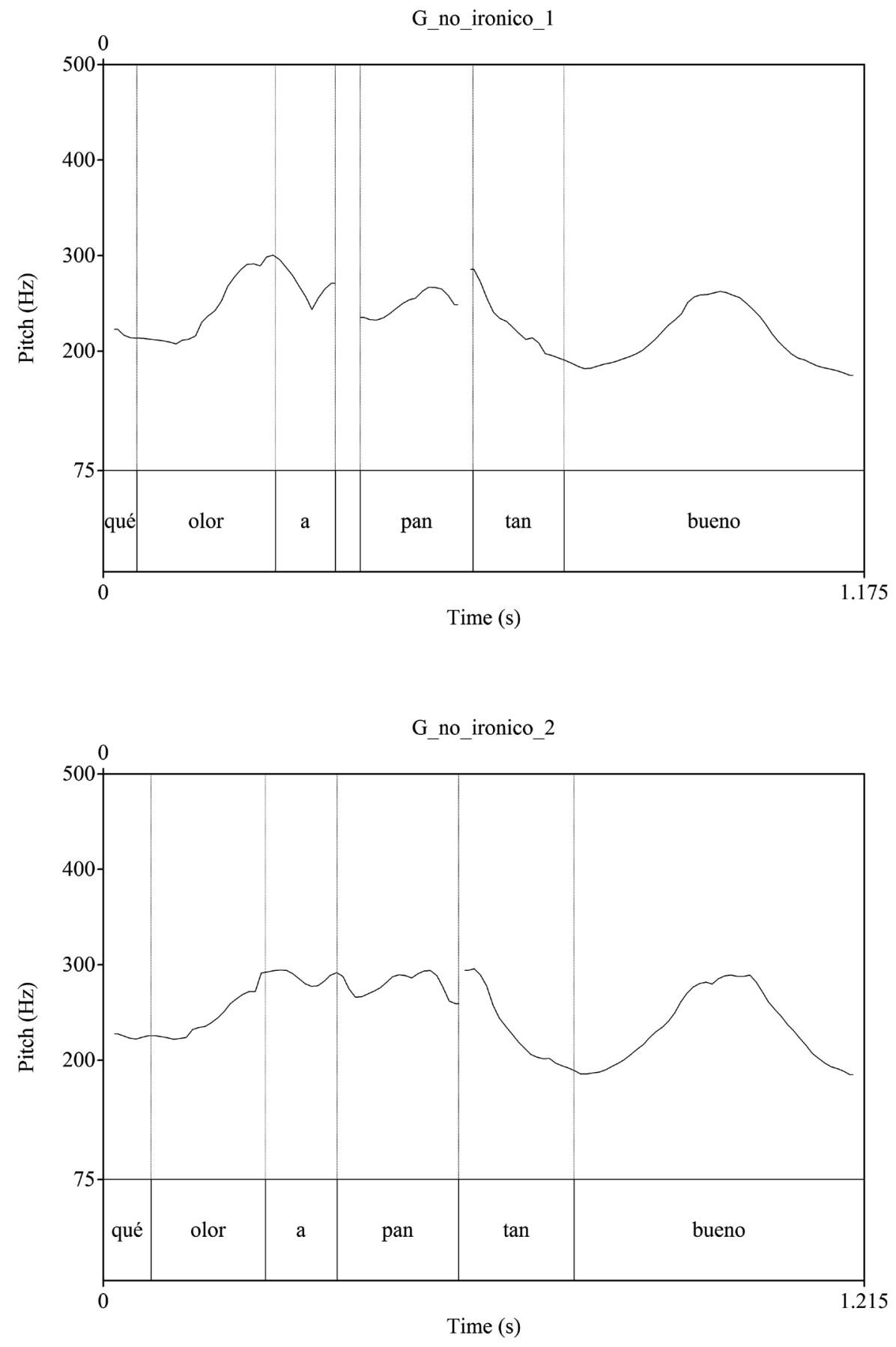

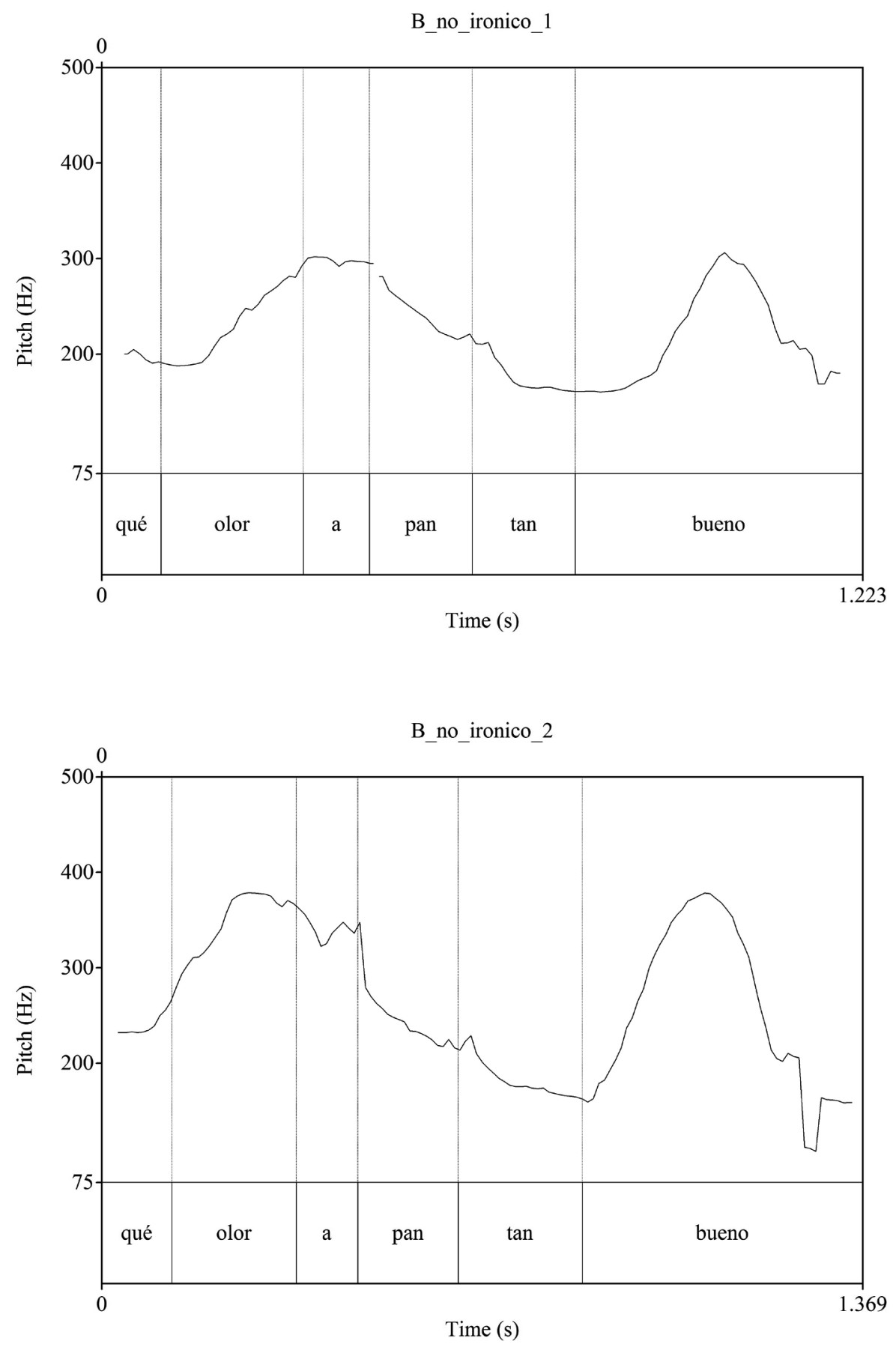


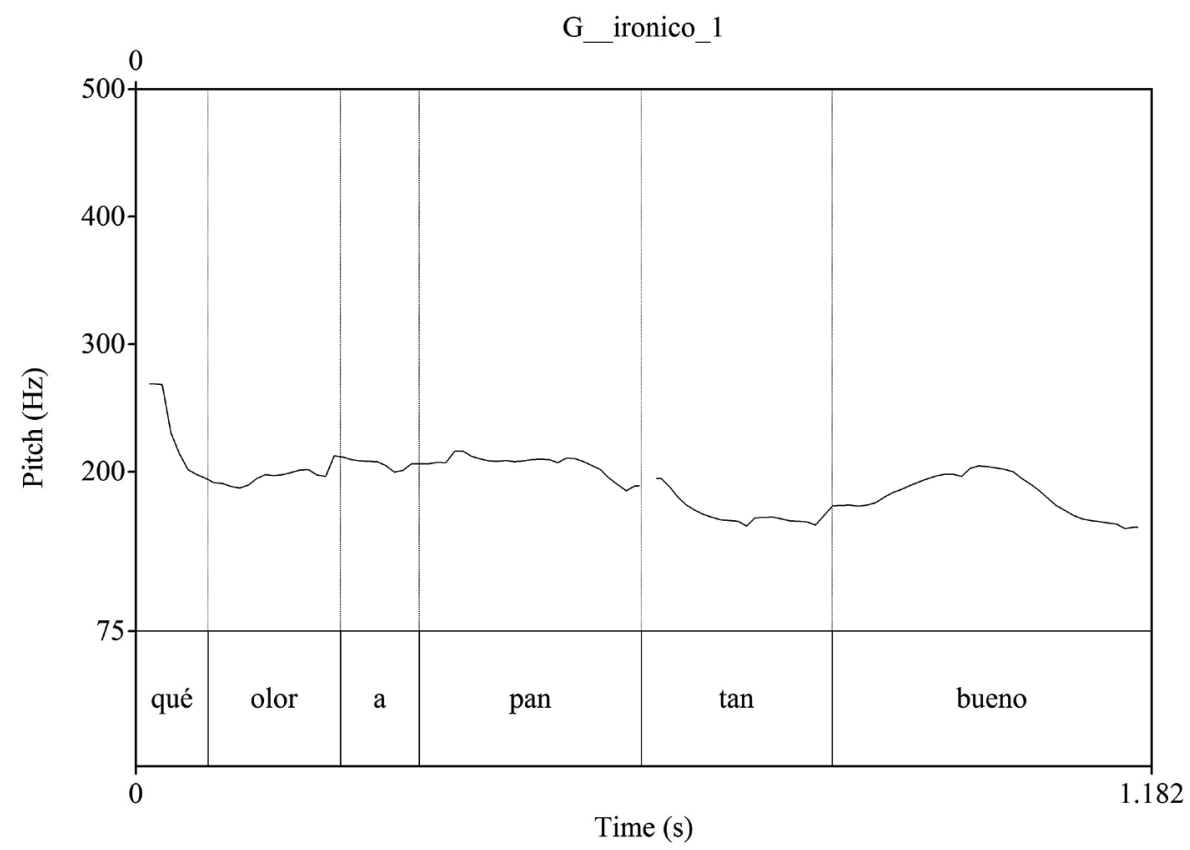

G_ironico_2

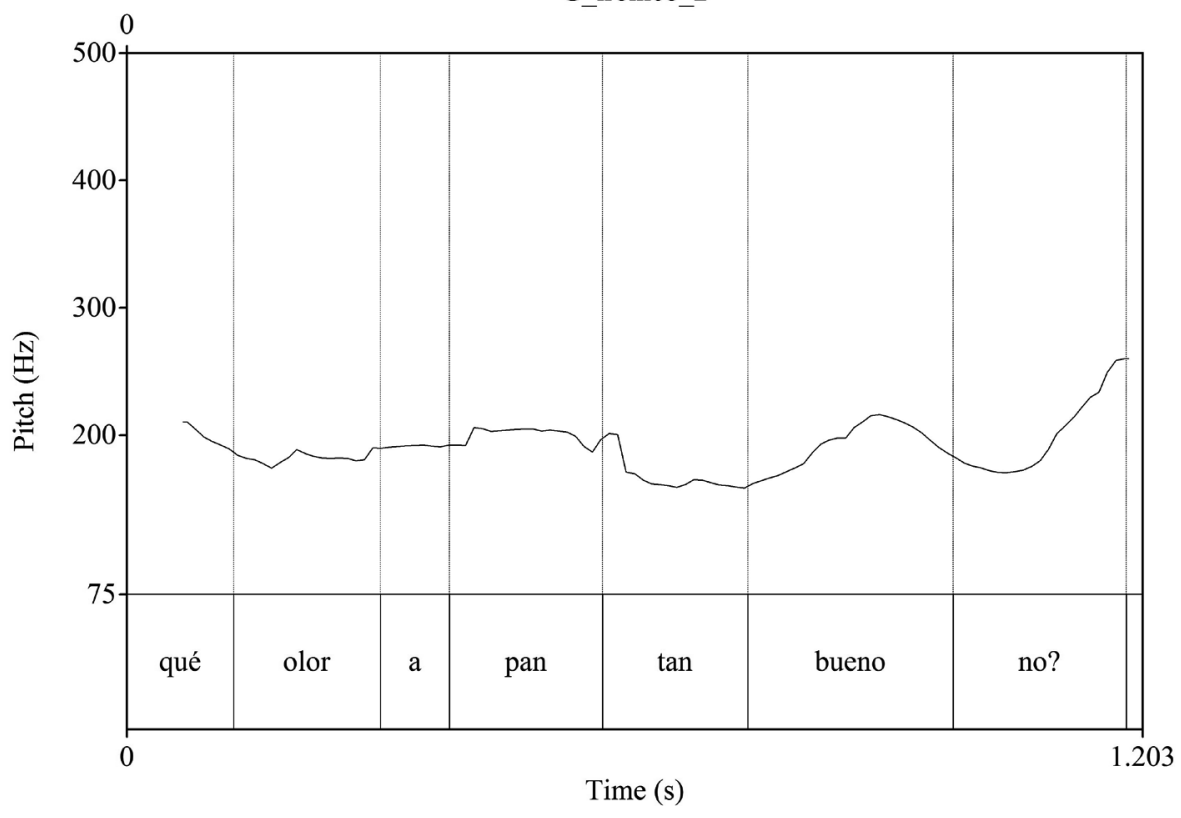



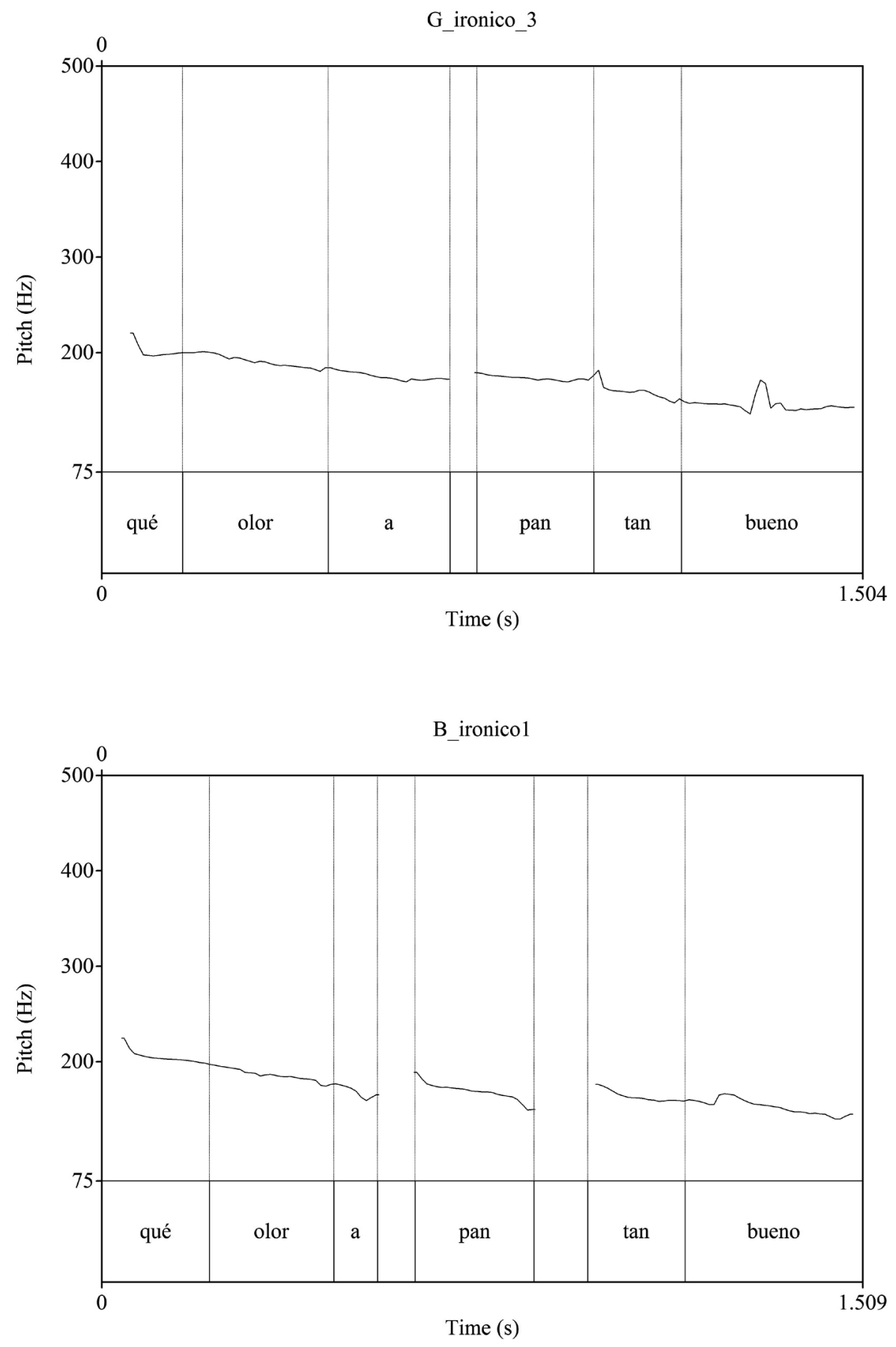

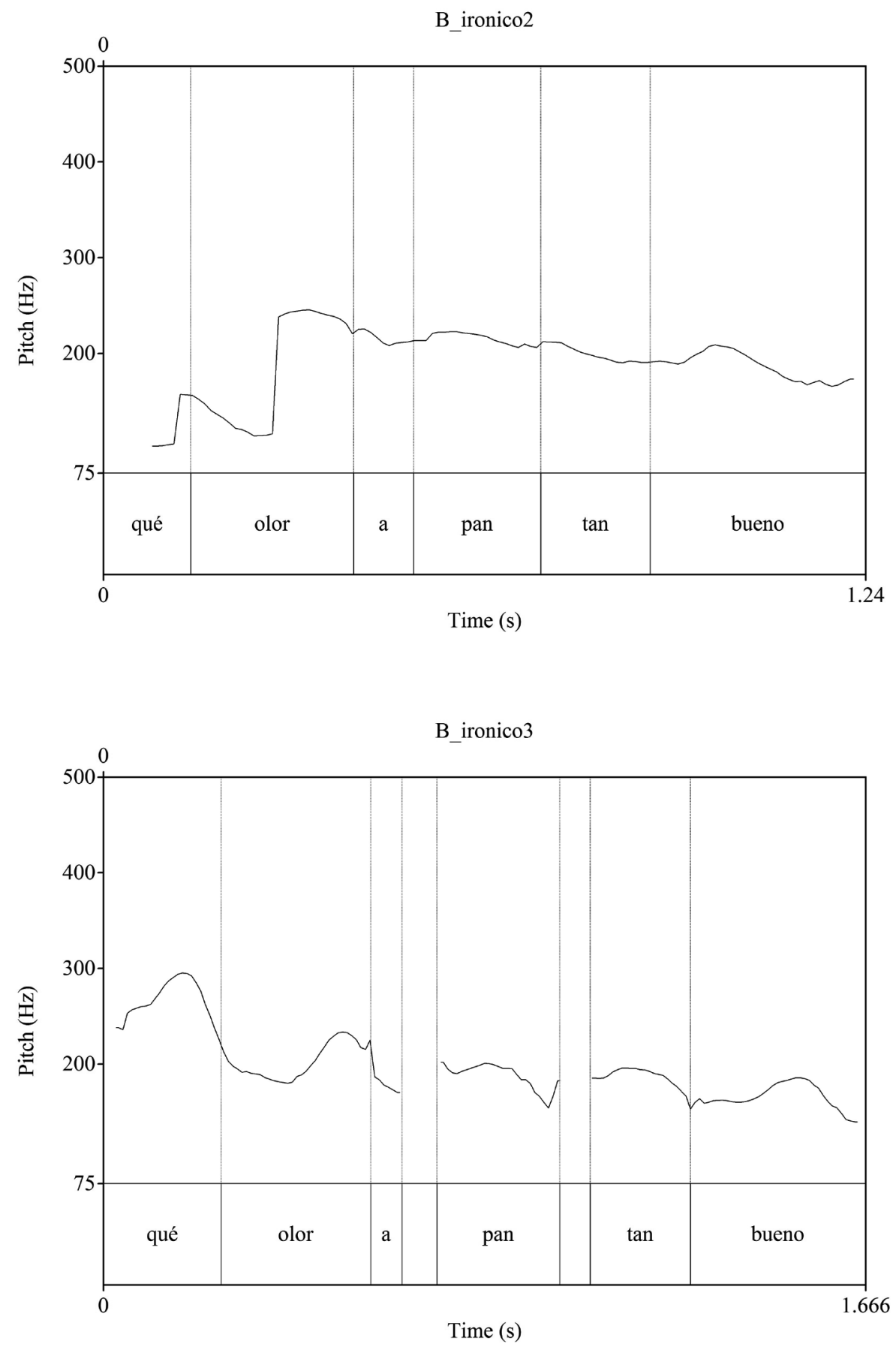